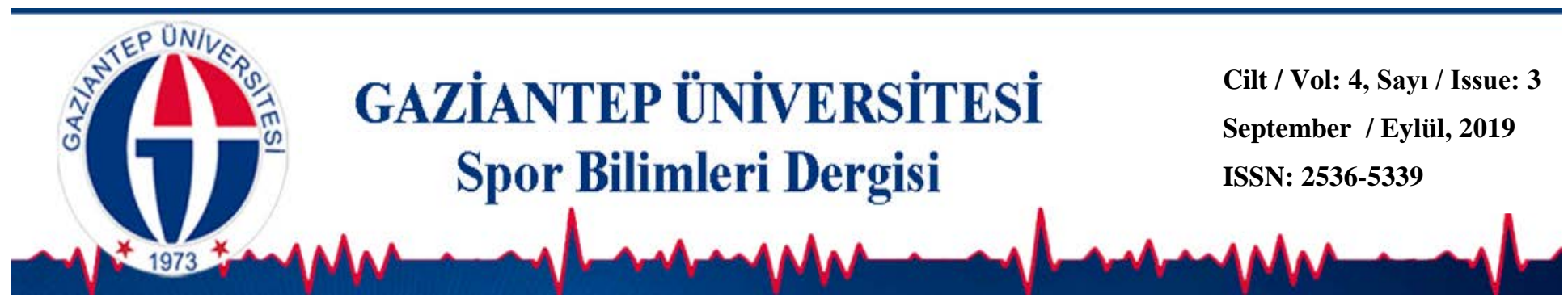

\title{
Kampüste Spor Deneyimi: Üniversite Öğrencilerinin Kampüs Rekreasyonel Spor Deneyiminin İncelenmesi
}

Hüseyin ÇEVIK ${ }^{1 *}$ (D)

\author{
Ecenur YILMAZ $^{1}$ iD \\ ${ }^{1}$ Eskişehir Teknik Üniversitesi, ESKIŞ̧EHIR
}

Ayberk KORKMAZ ${ }^{1}$ (D)

\section{DOI: 10.31680/gaunjss.594280}

Orijinal Makale / Original Article

Geliş Tarihi / Received: 19.07.2019
Kabul Tarihi / Accepted: 16.08.2019
Yayın Tarihi / Published: 22.09.2019

\section{Öz}

Kampüs rekreasyonel spor öğrencilerin çok yönlü gelişimine katkı sağlamaktadır. Bu gelişimin sağlanabilmesi için katılımın düzenli ve sürekli olması gerekir. Olumlu deneyim algısı katıımın düzenli ve sürekliğinde önemli rol oynamaktadır. Üniversiteler kampüs rekreasyonel spor programlarına katılımı arttırabilmek ve sürekliliği sağlamak için öğrencilerin deneyim algılarını değerlendirerek plan ve strateji geliştirmek durumundadır. Bundan dolayı bu araştırmada öğrencilerin kampüs rekreasyonel spor deneyim algılarının değerlendirilmesi amaçlanmıştır. Araştırmaya kolayda örnekleme yöntemi ile seçilen, Anadolu Üniversitesi ve Eskişehir Teknik Üniversitesi bünyesinde kampüs rekreasyonel spor aktivitelerine katılan 259 öğrenci dahil edilmiştir. Veriler oluşturulan anket aracılığı ile yüz yüze görüşme tekniği ile toplanmıştır. Anketin birinci bölümünde Kampüs Rekreasyonel Spor Deneyim Ölçeği, ikinci bölümde ise kişisel veriler formuna yer verilmiştir. Veri analizinde Doğrulayıcı Faktör Analizi (DFA), t-test ve ANOVA kullanılmıştır. Analiz sonuçları öğrencilerin kampüs rekreasyonel spor deneyim algılarının cinsiyet, fakülte/bölüm ve öğretim yıl değişkenlerine göre farklılaştığını ortaya koymuştur. Sonuç olarak araştırma bulguları, üniversite yönetimine kampüs rekreasyonel spor programı ile ilgili farklı özellikteki öğrencilerin ihtiyaç ve beklentilerinin anlaşılması noktasında önemli veriler sağlamaktadır.

Anahtar Kelimeler: Rekreasyonel spor, deneyim, kampüs rekreasyonu

\section{Sports Experience on Campus: Examination of University Students' Campus Recreational Sports Experience}

\begin{abstract}
The campus recreational sports programs contribute to the multi-faceted development of university students. Participation must be regular and continuous for this development. The perception of positive experience plays an important role in regular and continuous participation. Universities have to develop plans and strategies by evaluating students' perceptions of experience in order to increase participation in campus recreational sports programs and ensure continuity. Therefore, this study aimed to evaluate students' perceptions of campus recreational sports experience. The sample of the research consists of 259 students who participated in campus recreational sports within the Anadolu University and Eskişehir Technical University and were selected by convenience sampling method. The data was collected by the questionary using face to face interview technique. The first part of the questionary includes Campus Recreational Sports Experience Scale and in the second section, personal data form is given. The data were analyzed by Confirmatory Factor Analysis (CFA), t-test, and ANOVA. The results of the analysis revealed that students' perceptions of campus recreational sports experience differed according to gender, faculty/high school and academic year variables. As a result, the research findings provide important data for the university administration to understand the needs and expectations of students with different characteristics related to the campus recreational sports program.
\end{abstract}

Keywords: Recreational sport, experience, campus recreation

\footnotetext{
* Sorumlu Yazar: Hüseyin ÇEVİK

E-mail: huseyincevik@eskisehir.edu.tr *Bu Çalışma 11-14 Nisan 2019 tarihinde Bodrum, Muğla, Türkiye’ de düzenlenen II. Uluslararası Rekreasyon ve Spor Yönetimi Kongresinde sözel bildiri olarak sunulmuştur.
} 


\section{Giriş}

Öğrencilerin yükseköğretimdeki deneyimleri, öğrenciler ve eğitim kurumları arasında meydana gelen etkileşimler dizisine bağııdır. Bu deneyimler öğrencileri duygusal, fiziksel, ruhsal ve duyusal yönden etkilemekte, onlara bilgi, beceri kazandırmakta ve onların yeteneklerinin gelişimine yardımcı olmaktadır (Gentile ve ark., 2007). Bundan dolayı, üniversitelerin öğrencilerin gelişimine katkı sağlamak için farklı ve zengin deneyimleri öğrencilerine sunmaları gerekmektedir. Kampüs rekreasyonel spor program ve hizmetleri de bu deneyimler arasında yer almaktadır.

Kampüs rekreasyonel spor öğrenciler arasında fırsat eşitliğini sağlamak, farklı cinsiyet ve kültürden öğrencilerin spora katıımını artırmak, öğrencilerin sağlıklı yaşam tarzını geliştirmek, öğrenciler tarafından kampüste rekreasyon program ve tesislerini olan talebi karşılamak amacıyla ortaya çıkmıştır (Barcelona ve ark., 2016). Öğrencilere farkı yönlerden katkı sağladığı için üniversiteler tarafından oldukça önem verilmektedir (Belch ve ark., 2001). Barcelona ve diğ. (2016) göre kampüs rekreasyonel spor öğrencilere sağlıklı yaşam, fiziksel olarak yeterli olma ve beceri geliştirme imkanı sunmakta, üniversite tercihini ve eğitime devam etmelerini kolaylaştırmakta, liderlik ve birlikte öğrenme konusunda katkı sağlamaktadır.

Kampüs rekreasyonel spora katıımın öğrencilere sağladığı faydalar konusunda yapılan araştırmalar fiziksel sağlığa katkı sağlamasının dışında (Corbin ve Lindsey, 2005), akademik başarıda devamlılık sağladığı ve benlik imajını geliştirdiğini (Huesman ve ark., 2009), stresi azalttığını (Kanters ve Forrester, 2000), öz güveni arttırdığını (Evans ve ark., 2013), üniversiteye yönelik memnuniyet yarattığını (Forrester, 2006), sosyal etkileşim fırsatı sunduğunu (Belch ve ark., 2001) ve öğrencilerin sosyal bütünleşmesini desteklediğini (Artinger et al., 2006) göstermektedir. Bu faydaların elde edilebilmesinde öğrencilerin kampüs rekreasyonel spor programına düzenli katıım sağlamaları gerekmektedir. Düzenli katılım için olumlu deneyim algısının önemli rolünün olduğu düşünülmektedir. Çünkü pozitif deneyimler spora tekrar katıım ve sadakat oluşturmada rol oynamaktadır (Shin ve ark., 2018). Kampüs rekreasyonel spor bağlamında ise sunulan program ve hizmetlere yönelik deneyimlerin katılım sıklığı ve tesislerin kullanımı üzerinde güçlü bir etkisinin olduğu ifade edilmektedir (Hill ve Green, 2012; O'Reilly ve ark., 2015). Dolayısıyla, üniversitelerin kampüs rekreasyonel spora katıımı artıımak ve katıımı sürdürmek için, öğrencilerin deneyimlerini tüketici tanımlanmasında kullanılan 
demografik özelliklere göre değerlendirmelerinin önemli olacağı düşünülmektedir. Demografik özelliklere göre yapılacak değerlendirme geleceğe yönelik karar alma ve strateji geliştirme olanağı sağlamaktadır (Demir ve Kozak, 2013). Bu değerlendirmenin üniversite yönetimlerine başarılı kampüs rekreasyonel spor programları oluşturma ve sunma konusunda yardımcı olacağına inanılmaktadır.

Literatür incelemesinde araştırmaların kampüs rekreasyonel spor program ve hizmet deneyimine odaklandıkları gözlemlenmektedir (Ko ve Pastore, 2007; Shonk, 2010; Mercanoğlu ve ark., 2015; Abdullah ve Mohamad, 2016; Suttikun ve Chang, 2016; Çevik ve Şimşek, 2017). Deneyimin gerçekleştiği fiziksel ve sosyal çevrenin dikkate alınmadığı anlaşılmaktadır (Shin ve diğ. 2018). Bundan dolayı kampüs rekreasyonel spor deneyiminin fiziksel ve sosyal çevresinin değerlendirilmesine ihtiyaç duyulmaktadır (Shin ve diğ. 2018). Bu ihtiyacı gidermek için Shin ve ark. (2018) tarafından kampüs rekreasyonel spor deneyiminin sosyal ve fiziksel çevresini değerlendiren ölçme aracı geliştirilmiştir. Ancak bu konuda gerçekleştirilen araştırmaların sınırlı olması ve daha fazla araştırmaya intiyaç duyulmasında dolayı bu araştırmada, öğrencilerin katılımcı olarak tanımlanmasını kolaylaştıracak demografik özelliklere göre kampüs rekreasyonel spor deneyimlerinin incelenmesi amaçlanmıştır.

\section{Yöntem}

\section{Araştırmanın Modeli}

Araştırma süreci ilişkisel araştırma modeline göre tasarlanmıştır. Araştırma modelinde bağımsız değişkenler bağımlı değişken düzeylerine göre nedensel olarak karşılaştırılmıştır.

\section{Araştırma Grubu}

Araştırmanın örneklemi Anadolu ve Eskişehir Teknik Üniversitesi'nde kampüs rekreasyonel spor hizmetlerinden yararlanan öğrencilerinden oluşmaktadır. Zaman, maliyet, ulaşılabilirlik vb. sebeplerden dolayı kolayda örnekleme yöntemi ile seçilen 95 (36.5) kadın, 164 (63.1) erkek toplam 259 öğrenci araştırmaya dahil edilmiştir.

\section{Veri Toplama Araçları}

Veriler anket aracılığıyla toplanmıştır. Anketin birinci bölümünde "Kampüs Rekreasyonel Spor Deneyim Ölçeği," ikinci bölümünde ise kişisel veriler formuna yer verilmiştir. Kampüs Rekreasyonel Spor Deneyim Ölçeği Shin ve ark. (2018) tarafından geliştirilmiştir. Ölçek spor olayının fiziksel ve sosyal çevresine yönelik 
katılımcının bütünsel deneyimini değerlendirmektedir. Orijinal ölçme aracı spor dersleri (4 madde), spor tesisleri (4 madde), üniversite takımları (3 madde) ve okul spor kulüpleri (3 madde) olmak üzere dört alt boyuttan ve toplam 14 maddeden oluşmaktadır. Bu boyutlardan spor dersleri alt boyutu çeşitli fiziksel aktivite derslerine katılan öğrencilerin algısını ölçmektedir. Spor tesisleri, öğrencilerin kampüste yer alan spor tesislerine yönelik öğrencilerin kullanım deneyimini değerlendirmektedir. Üniversite takımları alt boyutu öğrencilerin üniversite, fakülte ve bölüm takımlarının performansına yönelik desteğini ölçerken, son alt boyut okul spor kulüpleri öğrencilerin kampüs rekreasyonel spor kapsamında yer alan spor kulüplerine katılım deneyimini değerlendirmektedir (Shin ve ark. (2018).

Araştırma kapsamında ölçme aracı önce Türkçe 'ye uyarlanmıştır. Bunun için önce Banville ve ark. (2000) önerdiği şekilde ölçekte yer alan maddeler iki dil uzmanı tarafından çeviri-geri çeviri tekniği ile İngilizce 'den Türkçe' ye, daha sonra Türkçe 'den İngilizce 'ye çevrilmiştir. Sonra çevirmenler ve araştırmacılar bir araya gelerek maddeleri değerlendirmiş ve onlara son şeklini vermiştir. Daha sonra çevirisi yapılan ölçme aracı Spor Bilimleri Fakültesinde öğrenim gören küçük bir örneklem grubuna uygulanmıştır. Maddelerde herhangi bir sorun olup olmadığı kontrol edildikten sonra veri toplama aşamasına geçilmiştir.

\section{Verilerin Toplanması}

Veriler 2019 yılı Mart ayı süresince anketörler aracılığıyla yüz yüze görüşme tekniği kullanılarak toplanmıştır. Veri toplam aşamasından önce anketörlere çalışmanın amacı ve anketin nasıl uygulanması gerektiği anlatılmıştır. Örnek uygulama yapıldıktan sonra veri toplama aşamasına geçilmiştir.

\section{Verilerin Analizi}

Veri analizine başlamadan önce veri setinin normal dağılım gösterip göstermediği basıklık ve çarpıklık katsayılarına göre değerlendirildi. Hesaplama sonucunda çarpıklık değerinin -.902 ve .040, basıklık değerinin ise -1.079 ve .509 arasında değiştiği tespit edildi. Normal dağılım için çarpıklık değerinin 3.0'dan, basıklık değerinin 10.0'dan küçük olması gerekmektedir (Kline, 2011). Buna göre verinin normal dağılım gösterdiği söylenebilir. Verinin normal dağılım gösterdiği anlaşıldıktan sonra Doğrulayıcı Faktör Analizi (DFA) ile ölçme aracının yapısı analiz edildi. Gruplar arası farkın yorumlanmasında parametrik testlerden t-test ve ANOVA analizleri kullanılmıştır. Grupların varyanslarının eşitliği Levene Testi ile kontrol 
edilmiştir. Grup varyanslarının eşit olduğu varsayımı karşılandığında, aradaki farkın kaynağını belirlemek amacıyla Post-Hoc testlerinden Bonferroni kullanılmıştır. Varyanslar eşit olmadığında ise Tamhane's T2'den yararlanılmıştır. Analiz sonucunda gruplar arası ortaya çıkan farkın etki büyüklüğü eta kare $\left(\eta^{2}\right)$ değeri ile yorumlanmıştır. Eta kare değeri $.010-.060$ arası küçük, .060 ve üstü orta, 0.140 ve üstü ise geniş etki anlamına gelmektedir (Green ve Salkind, 2005).

\section{Bulgular}

Araştırmada önce katıımcıların demografik özellikleri tespit edilmiştir. Bunun için yüzde ve frekans analizi kullanıımıştır. Tablo 1'de araştırmaya katılan örneklemin cinsiyet, eğitim gördükleri fakülte/yüksekokul, eğitim yılı ve aylık hane gelir düzeyine göre demografik özellikleri gösterilmektedir.

Tablo 1. Katıımcıların demografik özelliklerine göre frekans ve yüzde dağılımları.

\begin{tabular}{|c|c|c|c|c|c|}
\hline Demografik Özellik & $\mathbf{n}$ & $\%$ & Demografik Özellik & $\mathbf{n}$ & $\%$ \\
\hline Cinsiyet & & & Eğitim Yılı & & \\
\hline Erkek & 164 & 62.1 & Hazırık & 47 & 18.1 \\
\hline Kadın & 95 & 36.5 & Birinci sınıf & 57 & 21.9 \\
\hline Fakülte/Yüksekokul & & & İkinci sınıf & 59 & 22.7 \\
\hline Spor Bilimleri Fak. & & & Üçüncü sınıf & 59 & 22.7 \\
\hline Havacilık ve Uzay Bil. Fak. & 30 & 11.5 & Dördüncü sınıf & 38 & 14.6 \\
\hline İktisadi ve İdari Bilimler Fakültesi & 29 & 11.2 & Aylık Hane Geliri & & \\
\hline Mühendislik Fakültesi & 52 & 20.0 & $2000-3000 \mathrm{TL}$ & 55 & 21.2 \\
\hline Hukuk Fakültesi & 42 & 16.2 & $3001-4000 \mathrm{TL}$ & 66 & 25.4 \\
\hline İletişim Bilimleri Fakültesi & 30 & 11.5 & $4001-5000 \mathrm{TL}$ & 27 & 10.4 \\
\hline \multirow[t]{2}{*}{ Eğitim Fakültesi } & 33 & 12.7 & $5001-6000 \mathrm{TL}$ & 27 & 10.4 \\
\hline & 44 & 16.9 & 6001 ve daha yüksek & 31 & 11.9 \\
\hline
\end{tabular}

Tablo 1'de görüldüğü üzere, cinsiyet demografik özelliğine göre erkeklerin oranı kadınlardan daha fazladır. Fakülte/Yüksekokul özelliğine göre en fazla katııım \%20.0 ile İktisadi ve İdari Bilimler Fakültesi öğrencilerinden olmuştur. Eğitim yılına göre en çok ikinci (22.7) ve üçüncü sınıf (22.7), az ise dördüncü sınıf (\%14.6) öğrencileri katıım sağlamıştır. Aylık hane geliri özelliğine göre katıımcıların \%25.4'ü 3001 ve 4000 TL gelir grubundan gerçekleşmiştir.

\section{Ölçme Aracının Geçerlik ve Güvenirliğine Yönelik Bulgular}

Kampüs Rekreasyonel Spor Deneyim ölçeğinin yapısı DFA ile test edilmiştir. İlk analiz sonucunda faktör yükleri kontrol edilmiştir. Hair ve ark. (2013)'na göre faktör yükleri 0.50 'den yüksek olmalıdır. Üniversite takımları boyutu altında yer alan 9. Madde (9. Spor karşılaşmaları için desteklediğim takımın performansına odaklanırım) 0.41 faktör yük değerine sahip olduğu için bu madde çıkartılmıştır. Sonraki analizde 
kalan 13 maddenin faktör yüklerinin 0.50 'den yüksek olduğu gözlemlenmiştir (Tablo 2). Faktör yüklerinden sonra ölçüm modelinin veri ile uyumu, uyum indekslerine bakılarak değerlendirilmiştir. Uyum indekslerinin $\mathrm{X}^{2} / \mathrm{df}=1.400, \mathrm{CFI}=0.986, \mathrm{NFI}=0.954$, TLI=0.982, RMSEA=0.039, SRMR=0.0457 olduğu tespit edilmiştir. Veri ve model uyumunun söz konusu olabilmesi için ki kare/serbestlik derecesinin ( $X^{2} / \mathrm{df}$ ) 3.0'dan küçük olması gerekmektedir (Kline, 2011). CFI ve TLI'nın 0.95’i aşması, RMSEA değerinin 0.060'dan ve SRMR değerinin ise 0.08'den küçük olması beklenmektedir (Hu ve Bentler, 1999). NFI değerinin ise 0.90'ı aşması önerilmektedir ( Marsh ve ark., 2006). Uyum indeks değerleri referans değerler ile karşılaştırıldığında ölçüm modeli ve veri arasında uyum olduğu ifade edilebilir.

Ölçümün yapı geçerliği yakınsak ve ayrışma geçerlik analizleri ile değerlendirilmiştir. Yapı geçerliği için faktör yüklerinin kontrolü dışında ayrıca her bir boyutun ortalama açıklanan varyans (AVE) ve yapı güvenirliği hesaplanmıştır. Yakınsak geçerliğin sağlanabilmesi için AVE değerinin 0.50, yapı güvenirliğinin ise 0.70'den yüksek olması önerilmektedir (Hair ve ark., 2013). Analiz sonucunda bütün boyutların önerilen eşiği geçtiği görülmektedir (Tablo 2). Böylece ölçme aracının yakınsak geçerliği sağladığı ifade edilebilir.

Tablo 2. Ölçme aracının faktör yükleri, yapıların AVE, CR değerleri ve Cronbach's alpha katsayısı.

\begin{tabular}{|c|c|}
\hline Maddeler & $\begin{array}{l}\text { Faktör } \\
\text { Yükleri }\end{array}$ \\
\hline $\begin{array}{l}\text { Spor Dersleri, AVE= } 0.747, \text { CR=0.931, } \alpha=0.922 e \\
\text { Spor salonunu kullandıktan sonra fiziksel yetenek seviyemin arttığını hissederim. } \\
\text { Spor salonları fiziksel yeteneğimi geliştirmeme yardım ediyor. } \\
\text { Spor salonlarını kullandıktan sonra fiziksel formumun artıığını hissediyorum. } \\
\text { Spor salonlarında katılığım aktiviteler performans yeteneğimi geliştiriyor. }\end{array}$ & $\begin{array}{l}.840 \\
.888 \\
.888 \\
.845\end{array}$ \\
\hline $\begin{array}{l}\text { Spor Tesisleri, } \text { AVE=0.593, CR=0.853, } \alpha=0.852 \\
\text { Spor salonlarını temizliği gayet iyidir. } \\
\text { Spor tesislerinin dış görünüşü görsel olarak çok teşvik edicidir. } \\
\text { Spor salonundaki ekipman ve malzemelerin düzeni kullanışlıdır. } \\
\text { Spor salonlarındaki ıSı, hava akımı, gürültü ve koku gibi çevresel faktörler iyi durumdadır. }\end{array}$ & $\begin{array}{l}.710 \\
.787 \\
.784 \\
.796\end{array}$ \\
\hline $\begin{array}{l}\text { Üniversite Takımları, AVE=0.584, CR=0.719, } \alpha=0.650 \\
\text { Spor karşılaşmalarında benim için önemli olan tek şey takımın kazandığını görmektir. } \\
\text { Oyunun türü ne olursa olsun üniversite/fakülte takımımın kazanmasını isterim. }\end{array}$ & $\begin{array}{l}.502 \\
.957\end{array}$ \\
\hline $\begin{array}{l}\text { Okul Spor Kulüpleri, AVE=0.666, CR=0.899, } \alpha=0.851 \\
\text { Okul içi aktiviteler bana sosyal etkileşim için birçok olanak sağlar. } \\
\text { Okul içi katıldığım etkinliklerde birçok arkadaş edindim. } \\
\text { Okul içi aktivitelerde oluşan sosyal etkileşimden çok hoşlanırım. }\end{array}$ & $\begin{array}{l}.745 \\
.882 \\
.815\end{array}$ \\
\hline
\end{tabular}

Ayrışma geçerliği için boyutlar arası korelasyon değerleri hesaplanmıştır. Ayrışma geçerliğinin sağlanabilmesi için boyutlar arası korelasyon değerinin 0.90'ı 
aşmaması beklenmektedir (Hair ve ark., 2013). Korelasyon analizi sonucuna göre en düşük ilişkinin spor dersleri ve okul spor takımları $(r=0.162, p<0.01)$, en yüksek ilişkinin spor dersleri ve okul spor kulüpleri $(r=0.479, p<0.01)$ arasında olduğu tespit edilmiştir. Bu değerler ayrışma geçerliğinin sağlandığının göstergesidir. Geçerlik analizlerinden sonra Cronbach's alpha güvenirlik katsayısı hesaplanmıştır. Cronbach's alpha değerinin 0.70 'den yüksek olması yüksek güvenirlik olarak belirtilmektedir (Nunnaly ve Bernstein, 1994). Hem ölçeğin toplam (0.831), hem de boyutların Cronbach's alpha değeri 0.70 'den büyük olduğu için yüksek güvenirlik düzeyinden bahsedilebilir (Tablo 2). Analizler sonucunda ortaya çıkan sonuçlar ölçme aracının geçerli ve güvenilir olduğunu göstermektedir.

\section{Fark Analizlerine Yönelik Bulgular}

Tablo 2. Cinsiyet değişkenine göre kampüs rekreasyonel spor deneyiminin farklılaşma durumu.

\begin{tabular}{|c|c|c|c|c|c|c|c|}
\hline Faktörler & Cinsiyet & $\mathbf{n}$ & $\overline{\mathbf{X}}$ & SS & $\mathbf{t}$ & $\mathbf{p}$ & $\eta^{2}$ \\
\hline \multirow{2}{*}{ Spor Dersleri } & Kadın & 95 & 3.794 & .957 & \multirow{2}{*}{2.239} & \multirow{2}{*}{$.026^{*}$} & \multirow{2}{*}{.060} \\
\hline & Erkek & 164 & 3.509 & 1.007 & & & \\
\hline \multirow{2}{*}{ Spor Tesisleri } & Kadın & 95 & 3.907 & .888 & \multirow{2}{*}{2.792} & \multirow{2}{*}{$.006^{\star \star}$} & \multirow{2}{*}{.075} \\
\hline & Erkek & 164 & 3.588 & .886 & & & \\
\hline \multirow{2}{*}{ Üniversite Takımları } & Kadın & 95 & 3.624 & .890 & \multirow{2}{*}{0.968} & \multirow{2}{*}{.334} & \multirow{2}{*}{-} \\
\hline & Erkek & 164 & 3.510 & .931 & & & \\
\hline \multirow{2}{*}{ Okul Spor Kulüpleri } & Kadın & 95 & 3.624 & .909 & \multirow{2}{*}{2.314} & \multirow{2}{*}{$.021^{*}$} & \multirow{2}{*}{.074} \\
\hline & Erkek & 164 & 3.325 & 1.053 & & & \\
\hline
\end{tabular}

${ }^{* \star} \mathrm{p}<.01,{ }^{*} \mathrm{p}<.05$

Kampüs rekreasyonel spor deneyiminin cinsiyet değişkenine göre farklılaşma durumu incelendiğinde (Tablo 2), "spor dersleri $(t=2,239 / p<0.05)$ ", "spor tesisleri $(\mathrm{t}=2,792 / \mathrm{p}<0.01)$ " ve "spor kulüpleri $(\mathrm{t}=2,314 / \mathrm{p}<0.021)$ " boyutlarında anlamlı farklılığa rastlanılmıştır. Kadınların üç boyutta da ortalamalarının erkeklere göre yüksek olduğu saptanmıştır. Ete kare değeri ise üç boyutta da ortaya çıkan farkın $\left(\eta^{2}=.040, .075\right.$, .074) orta düzeyde olduğunu göstermektedir.

Tablo 3. Fakülte/Yüksekokul değişkenine göre kampüs rekreasyonel spor deneyiminin farklılaşma durumu.

\begin{tabular}{llllllll}
\hline Faktörler & Fakülte/Yüksekokul & $\mathbf{n}$ & $\overline{\mathbf{X}}$ & $\mathbf{S S}$ & $\mathbf{F}$ & $\mathbf{p}$ & $\mathbf{\eta}^{2}$ \\
\hline & Spor Bilimleri Fakültesi & 30 & 3.866 & 1.018 & & & \\
& Havacllı ve Uzay Bilimleri & 29 & 3.405 & 1.074 & & & \\
& Fakültesi & & & & \\
Spor & Iktisadi ve Idari Bilimler Fakültesi & 52 & 3.682 & 1.013 & 1.491 & .181 & - \\
Dersleri & Mühendislik Fakültesi & 42 & 3.690 & .865 & & & \\
& Hukuk Fakültesi & 30 & 3.366 & .962 & & & \\
& Iletişim Fakültesi & 33 & 3.856 & .968 & & & \\
& Eğitim Fakültesi & 44 & 3.437 & 1.041 & & & \\
\hline Spor & Spor Bilimleri Fakültesi & 30 & 4.158 & 1.022 & 3.375 & $.003^{\star \star}$ & .040 \\
\hline
\end{tabular}


Çevik H, Yılmaz E, Korkmaz A., (2019). Kampüste Spor Deneyimi: Üniversite Öğrencilerinin Kampüs Rekreasyonel Spor Deneyiminin İncelenmesi. Gaziantep Üniversitesi Spor Bilimleri Dergisi, 4(3), 346-359.

\begin{tabular}{|c|c|c|c|c|c|c|c|c|c|}
\hline \multirow[t]{6}{*}{ Tesisleri } & $\begin{array}{l}\text { Havacılık ve } \\
\text { Fakültesi }\end{array}$ & Uzay & Bilimleri & 52 & 3.405 & .848 & & & \\
\hline & İktisadi ve İdari & imler F & ültesi & 42 & 3.740 & .945 & & & \\
\hline & Mühendislik Fak & tesi & & 30 & 3.452 & .751 & & & \\
\hline & Hukuk Fakültesi & & & 33 & 3.583 & .810 & & & \\
\hline & İletişim Fakültes & & & 44 & 4.030 & .809 & & & \\
\hline & Eğitim Fakültesi & & & 30 & 3.659 & .900 & & & \\
\hline \multirow{7}{*}{$\begin{array}{l}\text { Üniversite } \\
\text { Takımları }\end{array}$} & Spor Bilimleri Fa & iltesi & & 30 & 3.788 & .960 & \multirow{7}{*}{1.194} & \multirow{7}{*}{.310} & \multirow{7}{*}{-} \\
\hline & $\begin{array}{l}\text { Havacılık ve } \\
\text { Fakültesi }\end{array}$ & Uzay & Bilimleri & 29 & 3.425 & .776 & & & \\
\hline & İktisadi ve İdari & imler F & ültesi & 52 & 3.628 & .892 & & & \\
\hline & Mühendislik Fak & tesi & & 42 & 3.674 & .863 & & & \\
\hline & Hukuk Fakültesi & & & 30 & 3.622 & .891 & & & \\
\hline & İletişim Fakültes & & & 33 & 3.373 & 1.046 & & & \\
\hline & Eğitim Fakültesi & & & 44 & 3.356 & .938 & & & \\
\hline \multirow{6}{*}{$\begin{array}{l}\text { Okul Spor } \\
\text { Kulüpleri }\end{array}$} & Spor Bilimleri Fa & iltesi & & 30 & 3.722 & 1.013 & \multirow{6}{*}{1.855} & \multirow{6}{*}{.089} & \multirow{6}{*}{-} \\
\hline & $\begin{array}{l}\text { Havacılık ve } \\
\text { Fakültesi }\end{array}$ & Uzay & Bilimleri & 29 & 3.275 & 1.087 & & & \\
\hline & İktisadi ve İdari & imler $F$ & ültesi & 52 & 3.653 & .970 & & & \\
\hline & Mühendislik Fak & tesi & & 42 & 3.269 & .917 & & & \\
\hline & Hukuk Fakültesi & & & 30 & 3.277 & .963 & & & \\
\hline & İletişim Fakültes & & & 33 & 3.626 & 1.063 & & & \\
\hline
\end{tabular}

${ }^{* \star} \mathrm{p}<.01,{ }^{*} \mathrm{p}<.05$

Kampüs rekreasyonel spor deneyiminin fakülte/yüksekokul değişkenine göre farklılaşma durumu incelendiğinde (Tablo 3), sadece "spor tesisleri ( $F=3.375$ / p<0.01)" boyutunda anlamlı farklılığa rastlanılmıştır. Gruplar arası karşılaştırmada ise Spor Bilimleri Fakültesinde öğrenim gören öğrencilerin ortalamasının $(X=4.158)$ diğerlerine göre daha yüksek olduğu tespit edilmiştir. Ortaya çıkan fark eta kare değerine göre $\left(\eta^{2}=.040\right)$ küçük düzeyde etki anlamına gelmektedir.

Tablo 4. Eğitim süresi değişkenine göre kampüs rekreasyonel spor deneyiminin farklılaşma durumu.

\begin{tabular}{|c|c|c|c|c|c|c|c|}
\hline Faktörler & Eğitim Yılı & $\mathbf{n}$ & $\overline{\mathbf{X}}$ & SS & $\mathbf{F}$ & $\mathbf{p}$ & $\eta^{2}$ \\
\hline \multirow{5}{*}{ Spor Dersleri } & Hazırlık & 47 & 3.489 & 1.034 & \multirow{5}{*}{1.235} & \multirow{5}{*}{0.297} & \\
\hline & Birinci sınıf & 57 & 3.684 & .878 & & & \\
\hline & İkinci sınıf & 59 & 3.432 & 1.068 & & & \\
\hline & Üçüncü sınıf & 59 & 3.762 & .907 & & & \\
\hline & Dördüncü sınıf & 38 & 3.743 & 1.120 & & & \\
\hline \multirow{5}{*}{$\begin{array}{l}\text { Spor } \\
\text { Tesisleri }\end{array}$} & Hazırlık & 47 & 3.335 & .892 & \multirow{5}{*}{3.223} & \multirow{5}{*}{$0.013^{*}$} & \multirow{5}{*}{.092} \\
\hline & Birinci sınıf & 57 & 3.859 & .873 & & & \\
\hline & İkinci sınıf & 59 & 3.868 & .827 & & & \\
\hline & Üçüncü sınıf & 59 & 3.775 & .824 & & & \\
\hline & Dördüncü sınıf & 38 & 3.598 & 1.053 & & & \\
\hline \multirow{5}{*}{$\begin{array}{l}\text { Üniversite } \\
\text { Takımları }\end{array}$} & Hazırlık & 47 & 3.510 & .916 & \multirow{5}{*}{0.198} & \multirow{5}{*}{0.939} & \\
\hline & Birinci sınıf & 57 & 3.543 & .954 & & & \\
\hline & İkinci sınıf & 59 & 3.502 & .914 & & & \\
\hline & Üçüncü sınıf & 59 & 3.638 & .901 & & & \\
\hline & Dördüncü sınıf & 38 & 3.561 & .910 & & & \\
\hline \multirow{5}{*}{$\begin{array}{l}\text { Okul Spor } \\
\text { Kulüpleri }\end{array}$} & Hazırlık & 47 & 3.305 & .977 & \multirow{5}{*}{0.794} & \multirow{5}{*}{0.530} & \\
\hline & Birinci sınıf & 57 & 3.555 & 1.041 & & & \\
\hline & İkinci sınıf & 59 & 3.339 & 1.038 & & & \\
\hline & Üçüncü sınıf & 59 & 3.559 & .919 & & & \\
\hline & Dördüncü sınıf & 38 & 3.368 & 1.098 & & & \\
\hline
\end{tabular}


${ }^{* *} \mathrm{p}<.01,{ }^{*} \mathrm{p}<.05$

Kampüs rekreasyonel spor deneyiminin eğitim yılı değişkenine göre farklılaşma durumu incelendiğinde (Tablo 4), sadece "spor tesisleri ( $F=3.375$ / p<0.01)" boyutunda anlamlı bir farklılığa rastlanılmıştır. Gruplar arası karşılaştırmada ise ikinci sınıf öğrencilerinin ortalamalarının $(X=3.868)$ diğerlerinden daha yüksek olduğu tespit edilmiştir. Ortaya çıkan fark eta kare değerine göre $\left(\eta^{2}=.092\right)$ orta düzeyde etki anlamına gelmektedir.

\section{Tartışma ve Sonuç}

$\mathrm{Bu}$ araştırmada kampüs rekreasyonel spor programlarına katılan ve hizmetlerinden yararlanan öğrencilerin cinsiyet, öğrenim görülen fakülte/yüksekokul, öğrenim süresi ve gelir değişkenine göre kampüs rekreasyonel spor deneyim algılarının değerlendirilmesi amaçlanmıştır. Araştırma bulgularına göre cinsiyet, fakülte/yüksekokul ve eğitim süresi değişkenlerine göre kampüs rekreasyonel spor deneyiminin farklılaştığı tespit edilmiştir.

Araştırmanın önemli sonuçlarından biri cinsiyet değişkenine göre kadınların kampüs rekreasyonel spor deneyim boyutlarından spor tesisleri ve spor kulüplerinde ortalamalarının yüksek olmasıdır. Spor tesisleri öğrencilerin beklentilerini karşılama, tatmin etme, yaşam kalitelerini arttırma vb. faydalarından dolayı üniversite yönetimleri açısından kampüslerde önemli bir role sahiptir (Shin ve ark., 2018). Yöneticiler kampüs rekreasyonu ile ilgili hizmetleri geliştirerek ve kaliteyi arttırarak sürekli olarak öğrencilerin ihtiyaç ve beklentilerini karşılama arayışı içerisindedir (Osman ve ark., 2006). Bu noktada kadınların kampüste yer alan spor tesisleri ve kampüs rekreasyonel sporun bir parçası olan kulüpler konusunda beklentilerinin karşılandığı ifade edilebilir. Milton ve Patton (2011) ile Watson ve ark. (2006) yaptıkları araştırmada kampüs rekreasyonel spor katılımcılarının çoğunluğunun erkek olduğu raporlanmıştır. Bu çalışmaya katılanların çoğunluğu da (\%62.1) erkek öğrencilerden oluşmaktadır. Dolayısıyla üniversite yönetimlerine katılımcıların önemli bir bölümünü oluşturan erkek öğrencilerin kampüs rekreasyonel spor deneyim algılarını etkileyecek faktörleri dikkate almaları önerilebilir. Ayrıca Hoang ve ark. (2016) kampüs rekreasyonuna katıımda engeller ve kolaylaştırıcıları araştırdığı çalışmada, tesislerin kullanımında erkek öğrencilerin daha baskın olduğunu, kadın kullanıcıların bunu cinsiyet engeli olarak değerlendirdiklerini rapor etmiştir. Bu araştırma kapsamında ise kadın katılımcıların tesislerle ilgili olumlu deneyim algısına sahip olduğu 
anlaşılmıştır. Dolayısıyla, araştırmanın yürütüldüğü üniversitelerde kadınlar açısından kampüs rekreasyonel sporda cinsiyet engeli gibi bir algının olmadığı yargısına varılabilir. Aslında bu durum kampüs rekreasyonel sporun temel felsefesinden biri olan cinsiyet eşitliğini de (Barcelona ve ark., 2016) desteklemektedir.

Araştırmanın diğer önemli sonuçlarından biri üniversite eğitimlerinin birinci ve ikinci yılında olan öğrencilerin kampüs rekreasyonel spor deneyim boyutlarından spor tesisleri boyutunda ortalamalarının yüksek olmasıdır. Lindsey ve Sessoms (2006) kampüs rekreasyonel spor tesisleri ve programlarının üniversiteyi tercih etme ve devam etmedeki etkisini araştırdıkları çalışmada, eğitim süresinin başında ve sonunda olan öğrenciler için tesisler ve programların olmasın önemli olduğu rapor edilmiştir. Benzer bir sonuç NIRSA (National Intramural Recreational Sports Association) (2010)'nın gerçekleştirdiği araştırma ile Forrester (2015) tarafından Amerika'da 38 üniversitede yürütülen araştırmada da ortaya koyulmuştur. Katılımcıların sırasıyla 3/2'si ve \%30'u tarafından üniversite eğitimine devam etmede kampüs rekreasyonel spor tesisleri ve programlarının önemli olduğu sonucuna ulaşılmıştır. Dolayısıyla öğrenim sürelerinin birinci ve ikinci yılında olanların üniversite eğitimlerine devam etmede konusunda kampüs rekreasyonel spor deneyiminin etkisinin olabileceği düşünülebilir. Ayrıca, kampüs rekreasyonel sporun öğrencilerin üniversiteden memnuniyet duyma ve üniversiteye karşı sadakat geliştirmesinde pozitif etkisi vardır (Lambrecht ve ark., 2009). Buradan hareketle eğitim sürelerinin başında olan öğrencilerin kampüs rekreasyonel spor programlarının sadık katılımcıları olabileceği ifade edilebilir. Üniversite eğitimlerinin sonunda olan öğrencilerin olumlu deneyim algıları için üniversite yönetimlerine bu noktada strateji ve planlarını gözden geçirmeleri önerilebilir.

Araştırmanın bir başka sonucu ise öğrenim görülen fakülte/yüksekokul değişkenine göre Spor Bilimleri Fakültesi öğrencilerinin kampüs rekreasyonel spor deneyimi boyutlarından spor tesislerinde ortalamalarının yüksek olmasıdır. Milton ve Patton (2011) demografik özelliklere göre kampüs rekreasyonel spor kullanıcılarını inceledikleri araştırmada sporcu olanların, kampüs rekreasyonel spor tesislerini kullanma oranının diğerlerine göre daha yüksek olduğunu raporlamıştır. Spor Bilimleri Fakültesi öğrencilerinin kampüs rekreasyonel spor tesislerini kullanma oranlarının yüksek olması, onların diğer fakülte ve yüksekokul öğrencilerine göre daha tecrübeli oldukları anlamına gelebilir. Tecrübeli kullanıcıların tesisler konusunda olumlu 
deneyime sahip olmaları, araştırmanın yürütüldüğü üniversitelerin spor tesislerinin beklentilere cevap verdiği şeklinde yorumlanabilir.

Sonuç olarak, bu araştırmada öğrencilerin kampüs rekreasyonel spor deneyim algısının cinsiyet, öğrenim görülen fakülte ve eğitim süresi değişkenlerine göre farklılık gösterdiği anlaşılmıştır. Kampüs rekreasyonel spor katılımcıları farklı özellikleri olan öğrencilerden oluşmaktadır. Dolayısıyla, üniversite yönetimleri farklılıkları dikkate alarak, istek ve beklentileri karşılayan kampüs rekreasyonel spor program ve hizmetlerini öğrencilere sunmalıdır. Böylece daha fazla öğrencinin kampüs rekreasyonel spora katılımı sağlanabilir. İleride yapılacak araştırmalarda öğrencilerin kampüs rekreasyonel spora katılımında rol oynayabilecek tatmin, davranışsal niyet (tekrar satın alma ve olumlu ağızdan ağıza iletişim), algılanan değer vb. yapılar ile deneyim algısı arasındaki ilişkilerin incelenmesinin önemli olduğu düşünülmektedir.

\section{Kaynaklar}

Abdullah, N., \& Mohamad, N. (2016). University recreational facilities service quality and students' physical activity level. Procedia-Social and Behavioral Sciences, 224, 207-212.

Artinger, L., Clapham, L., Hunt, C., Meigs, M., Milord, N., Sampson, B., \& Forrester, S. A. (2006). The social benefits of intramural sports. Naspa Journal. 43 (1), 69-86.

Banville, D., Desrosiers, P. and Genet-Volet, Y. (2000). Translating questionnaires and inventories using a cross-cultural translation technique. Journal of Teaching in Physical Education. 22 (3), 374-387.

Barcelona R. J., Mary S. W., Skye A. B. (2016). Recreational sport program design, delivery, and management. Champaign: Human Kinetics.

Belch, H. A., Gebel, M., \& Maas, G. M. (2001). Relationship between student recreation complex use, academic performance, and persistence of first-time freshmen. NASPA journal, 38(2), 254-268.

Corbin, C.B., \& Lindsey, R. (2005). Fitness for life (5th ed.). Champaign, IL: Human Kinetics

Çevik, H., Şimşek, K. Y., \& Yılmaz, İ. (2017). The evaluating of service quality in recreational sport events: kite festival sample. Pamukkale Journal of Sport Sciences. 8(1), 73-93. 
Demir Ş. Ş. ve Kozak M. (2013). Tüketici Davranışları. Ankara: Detay Yayıncılık.

Evans, K. E., Hartman, C. L., \& Anderson, D. M. (2013). It's more than a class: Leisure education's influence on college student engagement. Innovative Higher Education, 38(1), 45-58.

Forrester, S. (2006). An examination of the factors contributing to student satisfaction with their overall academic experience. Schole: A Journal of Leisure Studies and Recreation Education. 21(1), 21-33.

Forrester, S. (2015). Benefits of collegiate recreational sports participation: Results from the 2013 NASPA assessment and knowledge consortium study. Recreational Sports Journal. 39(1), 2-15.

Gentile, C., Spiller, N., \& Noci, G. (2007). How to sustain the customer experience: An overview of experience components that co-create value with the customer. European Management Journal, 25(5), 395-410.

Green, S., \& Salkind, N. (2005). Using SPSS for Windows and Macintosh: Understanding and analysing data. Upper Saddle River, NJ, Prentice-Hall.

Hair J.F., Black W.C., Babin B.J., Anderson R. E. (2013). Multivariate data analysis (Seventh Edition). Harlow: Pearson.

Hill, B., \& Green, B. C. (2012). Repeat participation as a function of program attractiveness, socializing opportunities, loyalty and the sportscape across three sport facility contexts. Sport Management Review, 15(4), 485-499.

Hoang, T. V., Cardinal, B. J., \& Newhart, D. W. (2016). An Exploratory Study of Ethnic Minority Students' Constraints to and Facilitators of Engaging in Campus Recreation. Recreational Sports Journal, 40(1), 69-81.

Huesman Jr, R., Brown, A. K., Lee, G., Kellogg, J. P., \& Radcliffe, P. M. (2009). Gym bags and mortarboards: Is use of campus recreation facilities related to student success? NASPA Journal, 46(1), 50-71.

$\mathrm{Hu}$, L. and Bentler, P. (1999), Cutoff criteria for fit indexes in covariance structure analysis: Conventional criteria versus new alternatives, Structural Equation Modeling, 6, (2), 1-55.

Kanters, M. A., \& Forrester, S. (2000). Recreational sport participation as a moderator of college stress. Recreational Sports Journal, 24(2), 11-24.

Kline, R. B. (2011). Principles and practice of structural equation modeling (Third Edition). New York: Guilford Press. 
Ko, Y. J., \& Pastore, D. L. (2007). An instrument to assess customer perceptions of service quality and satisfaction in campus recreation programs. Recreational Sports Journal, 31(1), 34-42.

Lambrecht, K. W., Kaefer, F. \& Ramenofsky, S. D. (2009) Sportscape factors Influencing spectator attendance and satisfaction at a Professional Golf Association tournament. Sport Marketing Quarterly, 18, (3), 165-172.

Lindsey, R., \& Sessoms, E. (2006). Assessment of a campus recreation program on student recruitment, retention, and frequency of participation across certain demographic variables. Recreational Sports Journal, 30(1), 30-39.

Marsh, H.W., Hau, K.T., Artelt, C., Baumert, J., \& Peschar, J.L. (2006). OECD's brief self-report measure of educational psychology's most useful affective constructs: Cross-cultural, psychometric comparisons across 25 countries. International Journal of Testing, 6(4), 311-360.

Mercanoğlu, A.O., Çevik, H., ve Şimşek, K.Y. (2015). Kampüs rekreasyonu kapsamında düzenlenen sportif rekreasyon etkinliklerinin hizmet kalitesinin değerlendirilmesi: Anadolu Üniversitesi Örneği. Akademik Sosyal Araştırmalar Dergisi, 3(9), 256-267.

Milton, P. R., \& Patton, B. J. (2011). Who enters campus recreation facilities: A demographic analysis. International Journal of Sport Management, Recreation and Tourism, 7, 11-29.

National Intramural Recreational Sports Association. (2010). NIRSA/NASPA Consortium campus recreation impact study. http://www.nirsa.org/docs/Discover/Research/Campus_Rec_Impact_(Erişim Tarihi 04.04.2019).

Nunnally, J. C. ve Bernstein, I. H. (1994). Psychometric Theory. New York: McGrawHill.

O’Reilly, N., Berger, I. E., Hernandez, T., Parent, M. M., \& Séguin, B. (2015). Urban sportscapes: An environmental deterministic perspective on the management of youth sport participation. Sport Management Review, 18(2), 291-307.

Osman, R. W., Cole, S. T., \& Vessel, C. R. (2006). Examining the role of perceived service quality in predicting user satisfaction and behavioral intentions in a campus recreation setting. Recreational Sports Journal, 30 (1), 20-29. 
Suttikun, C., \& Chang, H. J. (2016). College Students' Satisfaction and Involvement with the Recreation Center Based on Perceived Service Quality: The Moderating Effects of Health and Weight Consciousness. Recreational Sports Journal, 40(2), 179-192.

Shin, S., Chiu, W., \& Lee, H. W. (2018). For a better campus sporting experience: Scale development and validation of the collegiate sportscape scale. Journal of Hospitality, Leisure, Sport \& Tourism Education, 22, 22-30.

Shonk, D. J., Carr, J. W., \& De Michele, P. E. (2010). Service quality and satisfaction within campus recreation: The moderating role of identification. Recreational Sports Journal, 34(1), 9-23.

Watson, J., Ayers, S., Zizzi, S., \& Naoi, A. (2006). Student recreation centers: A comparison of users and non-users on psychosocial variables. NIRSA Journal, 30(1): 9-20. 